\title{
Injectable heroin - effective treatment for opiate misusers, but is it cost-effective? ${ }^{\dagger}$
}

Rachael M. Hunter and Sherife Hasan

\begin{abstract}
Summary
Implementation of injectable heroin treatment for patients with chronic heroin dependence unresponsive to oral methadone maintenance treatment has stagnated, even though the evidence for its effectiveness in this population continues to accrue. This is due to a range of political and environmental factors, not least of which is the cost of the treatment. The article by Byford et al in this issue of the Journal goes some way to increasing the evidence base for the cost-effectiveness of injectable heroin treatment compared with other treatment options. Questions still remain though about the funding implications for government departments, commissioners and providers, given that the sector that is responsible for the majority of the cost, healthcare, is not the same sector that sees the majority of the cost savings, criminal justice.
\end{abstract}

\section{Declaration of interest}

R.M.H was previously employed by South London and Maudsley NHS Foundation Trust and was involved in the contracting of services for their Addictions department. She worked for the Department of Health, Offender Health unit from 2006 to 2009 and was a member of the Project Team for the Prison Drug Treatment Strategy Review group. S.H. previously worked in both the Home Office and the Department of Health's Substance Misuse Policy Teams and Offender Health Team, where she led the national drug system change pilot scheme and the Prison Drug Treatment Strategy Review Group. Prior to this she worked as a social worker with children and young people, including young offenders and within the drug and alcohol treatment sector.
Rachael M. Hunter (pictured) is a health economist at Priment Clinical Trials Unit, University College London. Sherife Hasan is the Programme Director for Community Innovations Enterprise LLP.

Injectable heroin has been shown to be more effective than oral methadone in the treatment of chronic opiate addiction in repeated studies. ${ }^{1}$ Despite the increasing evidence for the effectiveness of injectable heroin, its use as a treatment option has remained minimal. Additionally, the significant cost of injectable heroin means that the cost-effectiveness of this intervention is less clear, particularly in comparison with the cheaper alternative, injectable methadone. ${ }^{2}$

Chronic opiate addiction is associated with significant costs to society and the individual. In the UK, drug-related government expenditure totalled $\mathfrak{E} 1.1$ billion in $2010 / 11$, with an estimated additional $\mathfrak{E} 6.3$ billion in public expenditure in 2010/2011 associated with the correlated, but not necessarily causally related, impact of drugs such as crime, physical and mental healthcare, social care and welfare payments. ${ }^{3}$ The percentage of spend accounted for by chronic opiate addiction is hard to quantify, but it is likely to be significant. The cost of chronic opiate addiction is not just fiscal, but also human, with opiate addiction being associated with higher rates of mortality ${ }^{4}$ and a higher prevalence of mental health problems ${ }^{5}$ and blood-borne viruses as a result of high-risk behaviours associated with injecting and needle sharing. ${ }^{6}$ Opiate addiction also has implications for the next generation, with the children of parents who misuse drugs having poorer cognitive, physical and psychological outcomes, as well as a higher probability of becoming substance misusers themselves. ${ }^{7}$

Oral methadone has remained the most common method of treatment for opiate addiction in the UK. Although a range of treatment options for opiate addiction are available in the UK, $5-10 \%$ of people receiving treatment for opiate dependence do

†See pp. 341-349, this issue. not respond to standard care. These people represent a more complex group, with a mean length of time taking opiates of 17 years, having received treatment for an average of 10 of those years. Moreover, $73 \%$ have spent some time in prison and $95 \%$ are unemployed. ${ }^{2}$ Injectable heroin has been a medical treatment since Bayer first released it as the trade name for the drug diamorphine in $1898 .^{8}$ It is a potential treatment alternative to oral methadone, but in the UK it can only be prescribed by a small number of registered general practitioners who require a Home Office licence.

As a result of a range of uncertainties about the further implementation of injectable heroin in the UK, the Randomised Injectable Opiate Treatment Trial (RIOTT) was established, led by the Institute of Psychiatry and Professor John Strang. The results showed that the primary treatment outcome was significant and effective, with $72 \%$ of participants randomised to injectable heroin returning a negative urine sample for street heroin in greater than 50\% of samples at 14-26 weeks after starting treatment compared with $27 \%$ in the oral methadone group and $39 \%$ in the injectable methadone group. ${ }^{9}$ However, in terms of value for money the results are less clear, as injectable heroin is four times the cost of oral methadone. This is partly due to the cost of the medication, but also because of the additional dispensing and supervision costs with an emphasis on ensuring that the heroin does not enter the illicit street market. ${ }^{2}$ Assessing the value for money of the treatment of drug misuse has an additional complexity given that the dialogue about appropriate resource allocation can sometimes play out more in the public than the scientific arena: debates about drug policy have a tendency to follow public opinion rather than the evidence base. ${ }^{1}$

\section{The limitations of randomised control trials}

Randomised controlled trials (RCTs) are considered by many as the gold standard in research, as the random allocation to treatment or control group is one of the best ways to reduce bias in research and give us the answers we are looking for. However, it 
is important to note that RCTs do have limitations, particularly in terms of making judgements about the results emerging from the perfect, protocolised environment of an RCT. RIOTT was designed as the optimum trial of the efficacy of injectable heroin and therefore it was not a typical drug treatment service found in the less perfect world of the drug treatment sector. Moreover, the aim was to detect a significant difference between treatment groups in the use of street heroin. Although one can infer that a reduction in the use of street heroin might be instrumental in reducing the probability of other negative health, criminal justice and social outcomes, the study was not designed to detect a difference between treatment groups for these outcomes. The economic evaluation published in this issue of the Journal is of value in that it provides a mechanism for pooling information across a wider range of outcomes into a 'cost per outcome gained' ratio. The aim of the analysis is then to answer the broader question: given the range of benefits seen by reducing the use of street heroin, is the extra cost of injectable heroin balanced by benefits seen in the individual, specifically patients' mortality and morbidity, but also through reduced costs in the community, most notably in the criminal justice system?

\section{Health and criminal justice outcomes in economic evaluations}

Most health economic evaluations are for interventions where the costs and outcomes are realised within the healthcare sector, sometimes extending as far as social care. An increased recognition of the need to ensure that limited government resources are spent on cost-effective interventions has seen an increase in the number of economic evaluations not just in healthcare, but also in education and other government agencies. This has resulted in a new level of complexity in the interpretation of a cost per outcome gained result, in particular the cost per quality-adjusted life-year (QALY), as used in Byford et al's analysis. This is because mortality and morbidity, the foundation of the QALY calculation, may not represent an outcome of interest, for instance in education, or may not cover all of the outcomes of interest, as in the treatment of opiate addiction. There are also implications for commissioners and providers of services who are responsible for the cost of the service but do not see all of the benefits. In the treatment of opiate addiction this is particularly challenging given that, as shown by Byford et al, injectable heroin and methadone were only costeffective compared with oral methadone if criminal justice costs were included.

\section{Who pays and what are the policy implications?}

This leaves the government in a quandary about how to demonstrate the health and social care benefits of an expensive treatment delivered and funded within a healthcare setting, although there are clearly the financial and social benefits of reducing crime.

In terms of injectable heroin specifically, the next step is not necessarily more research, but building on existing research. The evidence available on injectable heroin for this population should be synthesised away from a gold standard, as used in RIOTT, and into a simpler treatment model that better reflects treatment in a real-world service to see whether this has an impact on the cost-effectiveness of injectable heroin. Any new analyses should incorporate additional evidence of outcomes associated with longer follow-up and the findings of other published trials. The budget impact on government departments, providers and commissioners will also be an important consideration if the implementation of injectable heroin is ever to be more widespread. Either way, there is a consistent, strong argument for including criminal justice sector costs in cost-effectiveness analyses of illicit substance misuse treatments, even if the implications for commissioning drug treatment are unclear. Until then, policy and cost challenges remain for achieving wider roll out of what has been extensively demonstrated as a more effective treatment option for people with chronic opiate dependence unresponsive to oral methadone.

Rachael M. Hunter, MSC, Department of Primary Care and Population Sciences, University College London Medical School, UK; Sherife Hasan, MA, House of Lords, UK

Correspondence: Miss Rachael M. Hunter, Department of Primary Care and Population Sciences, University College London Medical School, Royal Free Campus, Rowland Hill Street, London NW3 2PF, UK. Email: r.hunter@ucl.ac.uk

First received 7 Oct 2012, final revision 19 Jun 2013, accepted 5 Sep 2013

\section{References}

1 Strang J, Babor T, Caulkins J, Fischer B, Foxcroft D, Humphreys K. Drug policy and the public good: evidence for effective interventions. Lancet 2012; 379: 71-83.

2 Byford S, Barrett B, Metrebian N, Groshkova T, Cary M, Charles V, et al. Cost-effectiveness of injectable opioid treatment $v$. oral methadone for chronic heroin addiction. Br J Psychiatry 2013; 203: 341-9.

3 Davies C, English L, Stewart C, Edginton M, McVeigh J, Bellis M A. United Kingdom Drug Situation: 2012 Edition. UK Focal Point on Drugs: Annual Report to the European Monitoring Centre for Drugs and Drug Addiction (EMCDDA). Department of Health, 2012.

4 Degenhardt L, Bucello C, Mathers B, Briegleb C, Ali H, Hickman M, et al. Mortality among regular or dependent users of heroin and other opioids: a systematic review and meta-analysis of cohort studies. Addiction 2011; 106: $32-51$.

5 Weich S, McBride O, Hussey D, Exeter D, Brugha T, McManus S. Latent class analysis of co-morbidity in the Adult Psychiatric Morbidity Survey in England 2007: implications for DSM-5 and ICD-11. Psychol Med 2011; 41: 2201-12.

6 Pouget ER, Hagan H, Des Jarlais DC. Meta-analysis of hepatitis C seroconversion in relation to shared syringes and drug preparation equipment. Addiction 2012; 107: 1057-65.

7 Bröning S, Kumpfer K, Kruse K, Sack P, Schaunig-Busch I, Ruths S, et al. Selective prevention programs for children from substance-affected families: a comprehensive systematic review. Subst Abuse Treat Prev Policy 2012; 7: 23.

8 Sneader W. The discovery of heroin. Lancet 1998; 352: 1697-99.

9 Strang J, Metrebian N, Lintzeris N, Potts L, Carnwath T, Mayet S, et al. Supervised injectable heroin or injectable methadone versus optimised oral methadone as treatment for chronic heroin addicts in England after persistent failure in orthodox treatment (RIOTT): a randomised trial. Lancet 2010; 375: 1885-95. 